\title{
Typical failure forms and improvement measures of power grid fasteners
}

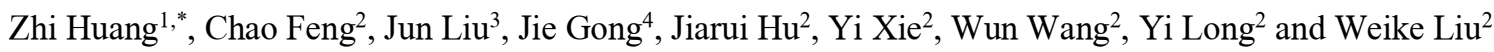 \\ ${ }^{1}$ State Grid Hunan Electric Power Company Limited Materials Company, Changsha 410004, China \\ ${ }^{2}$ State Grid Hunan Electric Power Company Limited Research Institute, Changsha 410007, China \\ ${ }^{3}$ State Grid Hunan Electric Power Corporation Limited Yueyang Power Supply Company, Yueyang 414000, China \\ ${ }^{4}$ State Grid Hunan Electric Power Company Limited Maintenance Company Changsha 410004, China
}

\begin{abstract}
By investigating the fastening defects of power grid components, it was concluded that unreasonable design, insufficient corrosion protection, improper assembly and insufficient fastening were the four typical forms of bolt failure. In response to the above problems, improvement measures such as design review, material sampling inspection, construction supervision, and operation and maintenance inspection were proposed.
\end{abstract}

\section{Introduction}

Fastener was an important connection method for diversion components, load-bearing components and sealing components in the power grid. They were widely used in primary equipment of the power grid [1]. Due to the large number of bolts and low cost, it had not received due attention in all aspects of the power grid system, resulting in frequent bolt fastening defects, which seriously affected the reliability, safety and stable operation of the primary equipment of the grid [2]. In order to improve the safe operation level of power grid equipment, corresponding improvement measures are proposed through analysis of typical failure modes of bolt fastening in this paper.

\section{Unreasonable design}

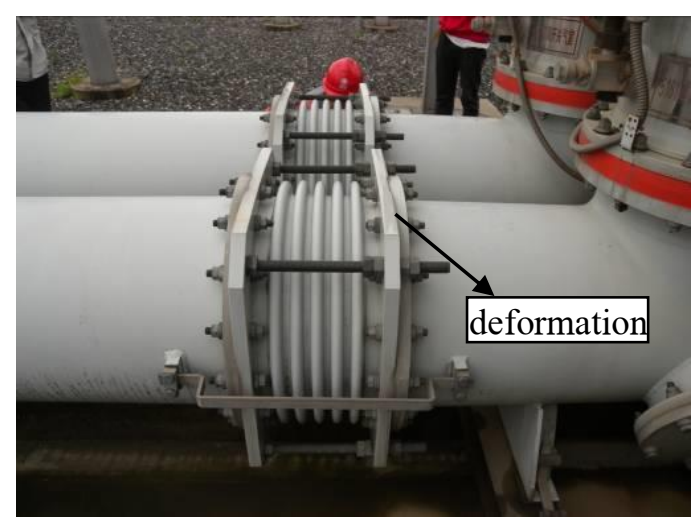

Fig. 1. Morphology of flange deformation.

The A leakage leakage defect occurred in the $126 \mathrm{kV}$ GIS bellows of a $110 \mathrm{kV}$ substation, and its model was ZF4-
110MGIS.Leakage was located at the joint between the bellows and the bus. The flange of the expansion joint of

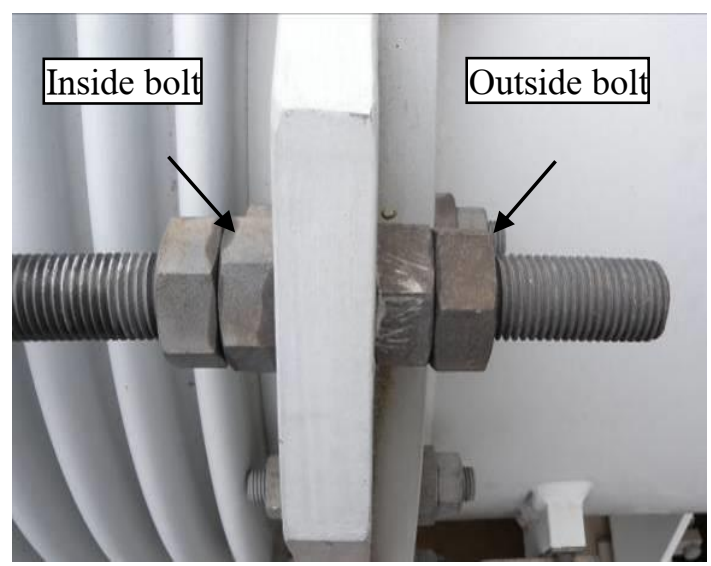

Fig. 2. Morphology of flange bolt fastening clearance.

GIS equipment had been deformed, as shown in Figure 1.

This type of bellows was an elastic element. It required a certain compensation bus bar sleeve expansion requirements during the design. The installation instructions indicated the clearance between the inner bolt (bellows side) and the flange plate to be 3$5 \mathrm{~mm}$, and the outer bolt (the tube side) didn't leave gaps to partially compensate for the axial expansion and contraction of the aluminum alloy cylinder. The on-site inspection of the fastening gaps between the bolts on both sides of the bellows flange plate and the flange plate found that the both-side bolts and the flange plate were locked and there was no clearance, as shown in Figure 2. By checking the installation information of the substation, the GIS equipment was installed and tested in summer. At that time, the temperature was high, and the aluminum alloy cylinder was in a thermal expansion

\footnotetext{
*Corresponding author: 27139902@qq.com
} 
state. The bellows was under compression, and the maximum difference in the annual temperature of the substation was about $40^{\circ} \mathrm{C}$. When the temperature was

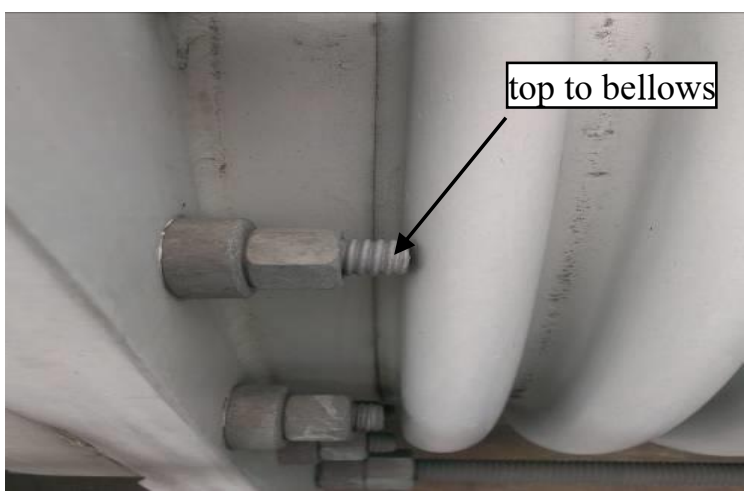

Fig. 3. Metallographic structure of thin walls of the flange.

low, the aluminum alloy cylinder shrunk and the screw directly distorted the flange plate through the outer bolts. The GIS bellows was under tensile stress. After the longterm operation, the weld between the bellows and the flange welds leaked.

In addition, there were also problems with the design of the fasteners on the inner side of the expansion joint. The screws of some fasteners were too long and had been pushed onto the body of the expansion joint, which would damage the outer surface when the expansion joint contracts, as shown in Figure 3.

\section{Insufficient corrosion protection}

In Grid fasteners often encounter corrosion problems during long-term service in outdoor atmospheric environments. Therefore, corresponding protection measures should be adopted in different corrosive environments. Galvanized technology and stainless steel are usually used for bolts. However, some manufacturers lacked the design process, or to reduce costs, or lack of careful consideration and strict requirements on the corrosion protection of bolts, leading to more problems in early corrosion failure.

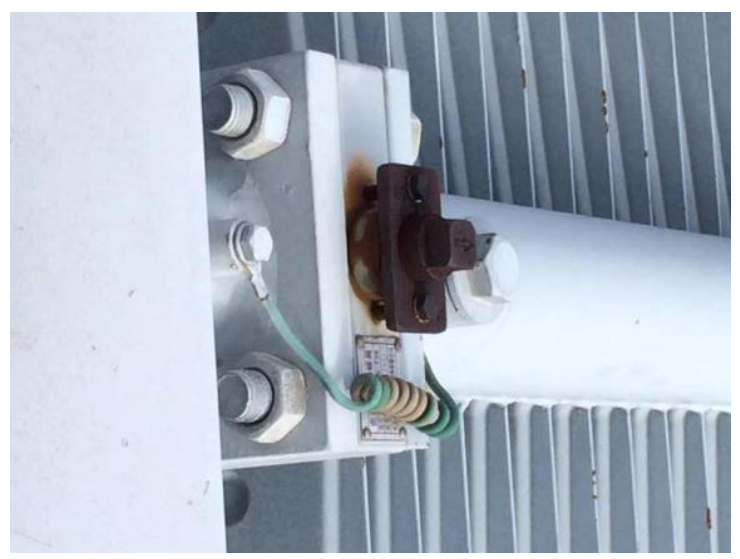

Fig. 4. Corrosion morphology of butterfly valve bolts.

A $220 \mathrm{kV}$ substation had been in operation for only 2 years. During the maintenance, it was found that the fasteners of the main transformer butterfly valve were severely rusted, as shown in Figure 4. The bolting process used was cold galvanized, and the anti-corrosion performance was not suitable for outdoor wet environments.

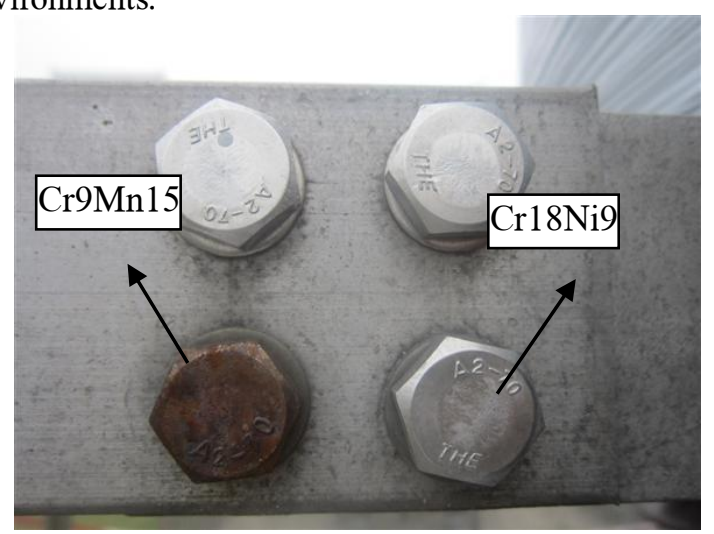

Fig. 5. Comparative appearance of stainless steel bolts of capacitor shunts.

In addition, the fastening bolts on the capacitor deflector of a $220 \mathrm{kV}$ substation were made of stainless steel, but the corrosion of the stainless steel bolts of the same component was in sharp contrast, as shown in Figure 5. The composition was tested with a hand-held alloy analyzer, as shown in Table 1. The main component of the rusted bolt was Cr9Mn15. Ni element was not found in the composition, but the Mn content was as high as 15\%. According to GB3098.6-2000 "Mechanical properties of fasteners, stainless steel bolts, screws, and studs" [3], rusted bolt was unqualified. The kind of high Mn stainless steel bolt was widely used in the power grid [4]. The unrusted stainless steel bolt was made of Cr18Ni9, which belonged to the typical austenitic stainless steel composition with excellent corrosion resistance.

Table 1. Components of the stainless steel bolts.

\begin{tabular}{|c|c|c|c|}
\hline Element & $\begin{array}{c}\text { non-rusted } \\
\text { bolt } / \%\end{array}$ & $\begin{array}{c}\text { rusted } \\
\text { bolt } / \%\end{array}$ & Standard $/ \%$ \\
\hline $\mathrm{Si}$ & 0.87 & 0.95 & $\leq 1.00$ \\
\hline $\mathrm{Mn}$ & 1.06 & 15.04 & $\leq 2.00$ \\
\hline $\mathrm{Cr}$ & 18.60 & 9.28 & $18.00 \sim 20.00$ \\
\hline $\mathrm{Ni}$ & 9.79 & - & $8.00 \sim 11.00$ \\
\hline $\mathrm{Fe}$ & Remain & Remain & Remain \\
\hline
\end{tabular}

\section{Improper assembly}

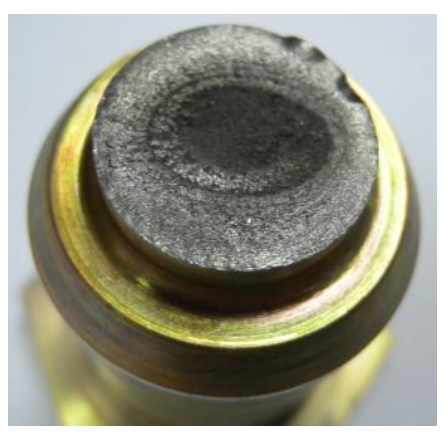

Fig. 6. Morphology of macro fracture of the bolt. 
Fasteners could also be used as load-bearing connections in power grid switching equipment, such as closing spring energy storage connecting rod bolts. In the event of improper bolt assembly, the force was significantly different from normal conditions. A $220 \mathrm{kV}$ circuit breaker A-phase closing spring energy storage connecting rod bolt broke during spring energy storage, as shown in Figure 6, causing the spring and the energy storage connecting rod and bolts to punch out of the circuit breaker back cover. The circuit breaker was operated in 2009 and the bolt design material was 42 CrMo steel.

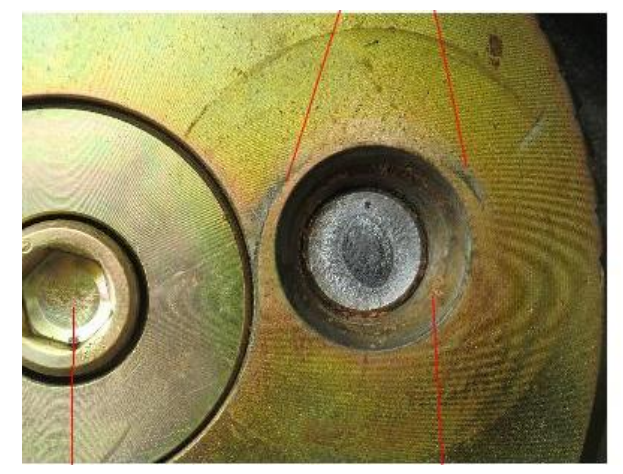

Fig. 7. Morphology of ratchet connected with the bolt.

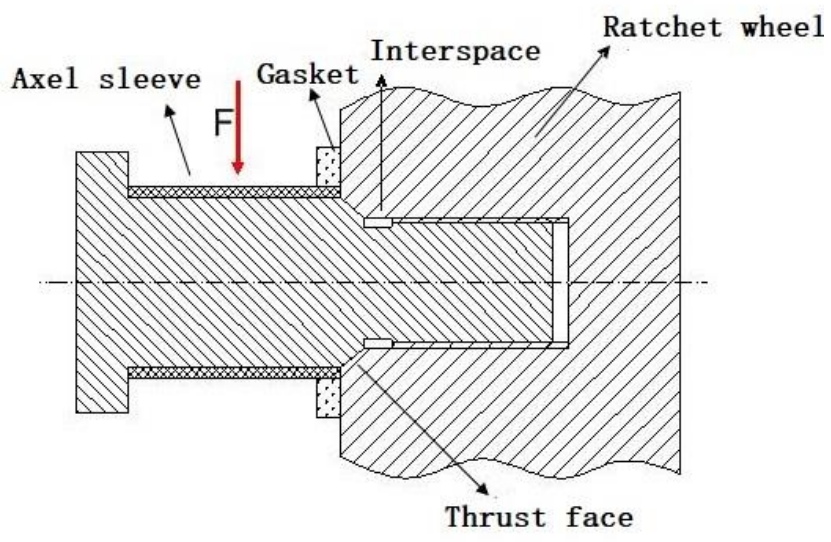

Fig. 8. Schematic diagram of correct assembly of bolts.

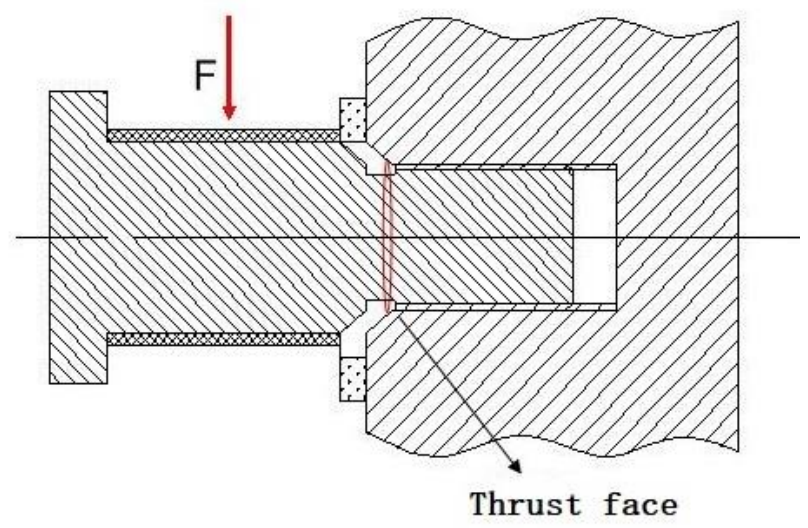

Fig. 9. Schematic diagram of incorrect assembly of bolts.
Fig. 7 had shown the photos of the accidental fault bolts left in the ratchet wheel. It could be clearly seen that the thrust bearing pad had a more obvious indentation left on the surface of the ratchet wheel, which could be inferred that the connecting rod bolt was incorrectly assembled. The correct assembly was shown in Figure 8. The gasket was sleeved on the shaft sleeve. It was in free contact with the surface of the ratchet and it was impossible to leave a residual indentation. In this case, the $45^{\circ}$ bevel of the bolt was tightly coupled to the $45^{\circ}$ bevel of the ratchet internal thread, which could effectively cushion the impact of the bolt root during the switch operation. However, the actual assembly was shown in Figure 9. The gasket was pressed under the sleeve, so that the $45^{\circ}$ slope of the bolt could not be coupled with the ratchet. In this way, the root of the bolt would be subjected to a large impact of additional bending moment stress when the switch was opened and closed, and eventually the root of the thread undercut would have a relatively rapid early low-cycle fatigue fracture.

\section{Insufficient fastening}

The tightness of the bolts of the grid deflection components directly affects the contact resistance of the connection parts, which results in different operating temperatures. The two sets of high-frequency protection channels of a $220 \mathrm{kV}$ line are abnormal. During the inspection, it was found that the drainage plate on the rear side of Phase A of Tower 107 of the line was burned out, as shown in Figure 10. The failure clamp drainage aluminum plate was connected by two bolts, and the fracture position was at the bolt connection. Obviously high temperature burns and melting deformations can be seen at the clip fracture and both bolts. In addition, the bolts and nuts was significantly rusted without spring and flat washers.

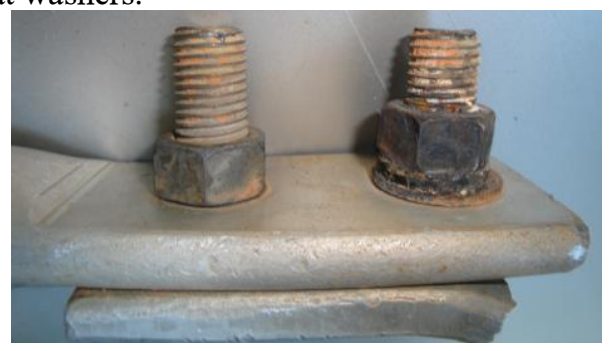

Fig. 10. Morphology of the failed clamp bolt.

Due to the above-mentioned quality defects in the installation process of the failed clamp, the bolt connection was loose and the local contact with the diversion caused the diversion area of the drainage plate to decrease during the operation. The temperature rose accordingly. Under the condition of a certain load, the clamp would gradually deform at high temperature until it melted. Because the melting point of aluminum is $660^{\circ} \mathrm{C}[5]$, which is much higher than the melting point of zinc, the corrosion-resistant galvanized layer of the connecting bolts has been melted before the aluminum plate is melted, causing serious corrosion of the bolts. 


\section{Improvement measures}

In view of the four types of typical failures and reasons of unreasonable design, inadequate corrosion protection, improper assembly and inadequate fastening, corresponding improvement measures had been proposed.

1)In the design liaison meeting, the design drawings of the sealing parts and expansion parts of the main transformer and GIS and other important equipment were reviewed to avoid the problems of poor sealing and poor expansion.

2)In the material procurement stage, the quality of galvanized coatings of stainless steel bolts and the quality of stainless steel bolts should be tested to ensure their anticorrosive performance.

3)During the construction phase, the gaskets, assembly methods, and tightening torques in the bolt assembly should be tested to ensure the installation quality. It is recommended to use a torque wrench to check the tightening force. At the same time, it is necessary to strengthen the training of field personnel for the importance of bolt installation to improve quality awareness.

4)In the operation and maintenance phase, infrared temperature measurement should be performed on the fastening bolts of the high current part during the peak load period, and important bearing forces and seals should be monitored to avoid heating, corrosion and leakage.

\section{References}

1. G.S.Xie, C.Liu, Y.Xie, Typical cases of failure of metal components in power grid equipment[M]. Beijing: China electric power press, 2015: 28-28.

2. H.B.Chen, Z.Huang, Y.Xie, C.Liu, G.S.Xie, Inner Mongolia Electric Power Techno. 12, 2(2012).

3. GB3098.6/ T-2000 Mechanical properties of fasteners, stainless steel bolts, screws, and studs[S].

4. Y.Xie, A.M.Xie, S.Z.Mou, J.R.Hu, Y.Long, Fastener Techno. 1, 3(2012).

5. Z.T.Wang, R.J.Tian, Aluminum alloy and its processing manual[M]. Changsha: Central south university press, 2000: 100-101. 